\title{
Determinação da concentração de diferentes sistemas de solventes na solubilização de proteínas de análogo de carne
}

\author{
Determination of the concentration of different solvents \\ systems in the protein solubilization of meat analogue
}

\section{Marcio Schmiele $^{I^{*}}$ Thiago Lopes Araújo $^{\mathrm{I}}$ Mônica Dubas Gurgueira ${ }^{\mathrm{I}}$ Yoon Kil Chang}

\section{RESUMO}

O uso de solventes especificos para extração de proteínas determina o tipo de reação química que ocorre entre os componentes proteicos, principalmente quando estes foram submetidos a tratamentos térmicos como a extrusão termoplástica, uma tecnologia de alta versatilidade, baixo custo, alta produtividade e que não gera efluentes. No entanto, é necessário o uso de concentrações adequadas dos solventes para maximizar a extração das proteinas. Neste trabalho foi avaliada a solubilização de proteinas de análogo de carne a base de isolado proteico de soja e glúten vital, submetidos ao processo de extrusão termoplástica a baixa (23\%) e alta (60\%) umidade. Os solventes utilizados foram: tampão fosfato $(\mathrm{pH} 7,5)$ de 10, 20, 40, 60, 80 e 100mM, dodecil sulfato de sódio de 1, 2, 3, 4 e 5\%, $\beta$-mercaptoetanol de 1, 2, 3 e 4\%, Triton X-100 de 1, 2, 3 e 4\% e ureia de 6, 7, 8, 9 e 10M. Todos os reagentes foram dissolvidos ou solubilizados em tampão fosfato $40 \mathrm{mM}(\mathrm{pH} 7,5)$. Os resultados mostraram que as maiores extrações proteicas foram obtidas com o uso de $40 \mathrm{mM}$ de tampão fosfato, $2 \%$ de dodecil sulfato de sódio, $2 \%$ de $\beta$-mercaptoetanol, $3 \%$ de Triton $X-100$ e $7 M$ de ureia.

Palavras-chave: solubilidade proteica, interação proteínaproteína, análogo de carne, proteína de soja, glúten vital.

\section{ABSTRACT}

The use of specific solvents for protein extraction determines the type of chemical reaction, which occurs between the protein components, mainly when the protein was submitted to thermal treatment, such as thermoplastic extrusion, a technology with high versatility, low cost and high throughput and without effluent generation. However, it is necessary to use adequate solvents concentration in order to maximize the protein extraction. The aim of this research was to evaluate the protein solubilization of meat analogue based on isolate soy protein and vital gluten submitted to thermoplastic extrusion process at low moisture content (23\%) and high moisture content (60\%). The solvents used were: phosphate buffer ( $\mathrm{pH}$ 7.5) at 10, 20, 40, 60, 80 and 100mM, sodium dodecyl sulphate at 1, 2, 3, 4 and 5\%, $\beta$-mercaptoethanol at $1,2,3$ and $4 \%$, Triton $X-100$ at $1,2,3$ and $4 \%$ and urea at 6, 7, 8, 9 and 10M. All the chemical reagents were dissolved or solubilized in phosphate buffer $40 \mathrm{mM}$ ( $p H$ 7.5). The results showed that the highest protein extraction were obtained when phosphate buffer $40 \mathrm{mM}$, sodium dodecil sulphate $2 \%$, $\beta$-mercaptoethanol $2 \%$, Triton $X-1003 \%$ and urea $7 M$ were used.

Key words: protein solubility, protein-protein interaction, meat analogue, soy protein, vital gluten.

\section{INTRODUÇ̃̃̃O}

O conhecimento sobre a solubilidade das proteínas é essencial para avaliar a funcionalidade proteicaeostiposdeinteraçõesquímicasocorridasentre as proteínas. Esta solubilidade é dependente de fatores intrínsecos (composição e sequência de aminoácidos) e extrínsecos $(\mathrm{pH}$, força iônica, temperatura e concentração do solvente) (SATHE, 2012). O uso de proteínas vegetais caracteriza a elaboração de extensores e/ou análogos de carne, sendo que este tipo de produto é manufaturado através da extrusão termoplástica, um processo de grande versatilidade, baixo custo, alta produtividade e que não proporciona a geração de efluentes (STEEL et al., 2012). A extrusão a baixa umidade de proteínas vegetais resulta em um produto que pode ser utilizado para substituir total ou parcialmente a carne em produtos cárneos. Este análogo de carne

'Departamento de Tecnologia de Alimentos, Faculdade de Engenharia de Alimentos (FEA), Universidade Estadual de Campinas (UNICAMP), Rua Monteiro Lobato, 80, 13083-862, Campinas, SP, Brasil. E-mail: marcio.ufpel@gmail.com. *Autor para correspondência. Recebido 11.12.13 Aprovado 11.10.14 Devolvido pelo autor 14.12.14 
sofre expansão e necessita de reidratação antes do consumo. A extrusão termoplástica a alta umidade produz análogos de carne que podem ser consumidos diretamente, sem a necessidade de reidratação (SCHMIELE et al., 2013b).

Dessa forma, a extrusão a baixa e alta umidade resulta em diferença na severidade do processamento, no grau de desnaturação das proteínas e nas modificações químicas ocorridas, sendo que, para analisar a solubilização proteica, pode requerer solventes com força iônica variada.

Os mecanismos de interações entre as proteínas podem ser avaliados através da ressolubilização dos agregados proteicos em solventes específicos. A proteína no estado nativo apresenta solubilidade em solução salina e em meio levemente alcalino $\left(\mathrm{SO}^{-2}, \mathrm{ClO}^{-1}, \mathrm{SCN}^{-1}\right.$, $\left.\mathrm{PO}^{-3}\right)$, as ligações dissulfídricas são rompidas com reagentes redutores $(\beta$-mercaptoetanol, ditiotreitol, $\mathrm{Na}_{2} \mathrm{SO}_{3}$ ), as ligações de hidrogênio são interrompidas com reagentes desnaturantes (ureia, tioureia, dimetilformamida), as interações hidrofóbicas são desestruturadas com reagentes detergentes aniônicos e catiônicos (dodecil sulfato de sódio, Triton, tioureia, CHAPS - 3-[(3-Cholamidopropyl) dimethylammonio]-1-propanesulfonate) e as interações eletrostáticas ou iônicas são rompidas com agentes tensoativos iônicos (dodecil sulfato de sódio) (LIN et al., 2000; CHIANG, 2007; LIU \& HSIEH, 2008; DAY \& SWANSON, 2013).

Em geral, os solventes são divididos em próticos e apróticos, sendo que cada um deles ainda pode ser polar e apolar. $\mathrm{O}$ solvente prótico polar contém um $\mathrm{H}^{+}$dissociável, enquanto que o solvente aprótico polar não possui átomos de hidrogênio com uma fraca ligação química. Dado o elevado momento dipolar, há uma separação de cargas positivas e negativas dentro de cada molécula, o que faz com que possam estabilizar os íons em solução por interação entra a carga iônica e o dipolo permanente. Esta propriedade é muito importante, pois determina os tipos de reações que os íons podem ter em solução, e, assim, podem interagir com o grupo hidroxila ou o grupo amina das proteínas.

Em reações químicas, o uso de solventes próticos polares favorece o mecanismo de reação $\mathrm{SN}_{1}$, enquanto que os solventes apróticos polares favorecem o mecanismo da reação $\mathrm{SN}_{2}$ (LOUDON, 2009). Solventes apróticos polares não apresentam a ligação de um átomo de hidrogênio a um elemento eletronegativo (SOLOMONS \& FRYHLE, 2005) e apresentam elevadas velocidades de reações do tipo $\mathrm{SN}_{2}$. O dodecil sulfato de sódio (SDS), o $\beta$-mercaptoetanol ( $\beta$-ME), o Triton $\mathrm{X}-100$ e a ureia são solventes apróticos polares e, por esta razão, muito utilizados em análises de solubilidade de proteínas, pois são capazes de solubilizar os cátions em $\mathrm{pH}$ alcalino.

O objetivo deste trabalho foi avaliar o efeito de diferentes concentrações de tampão fosfato $(\mathrm{pH} 7,5)$, SDS, $\beta$-ME, Triton X-100 e ureia na solubilização de proteínas de análogo de carne a base de isolado proteico de soja (IPS) e glúten vital (GV), obtido por extrusão termoplástica em condições de baixa $(23 \%)$ e de alta umidade $(60 \%)$.

\section{MATERIAL E MÉTODOS}

\section{Matéria-prima e composição centesimal}

O IPS (SUPRO $780^{\circledR}$ IP) e o GV $\left(\right.$ Viten $\left.^{\circledR}\right)$, ambos amostras comerciais, foram caracterizados quanto à composição centesimal em relação à umidade, proteína, cinzas e lipídeos através dos métodos 44-15.02, 46-13.01, 08-01.01 e 30-25.01 da AACC (2010), respectivamente. Carboidratos foram calculados por diferença.

\section{Extrusão termoplástica a baixa e a alta umidade}

As amostras foram extrusadas em extrusor dupla rosca corrotacional encaixado (ZSK 30 - Werner Pfleiderer Corp). A amostra extrusada a baixa umidade foi processada através da combinação de IPS:GV na proporção de 90:10, umidade de condicionamento de $23 \%$, temperatura de $1^{\mathrm{a}}$ e de $2^{\mathrm{a}}$ zona de 60 e $80^{\circ} \mathrm{C}$, respectivamente, $3^{\text {a e }} 4^{\text {a }}$ zona de $110^{\circ} \mathrm{C}$, vazão de alimentação de $9 \mathrm{~kg} \mathrm{~h}^{-1}$, velocidade de rosca de 300rpm e matriz circular com dois orifícios de $2,6 \mathrm{~mm}$ cada um. A extrusão à alta umidade foi processada por meio da combinação de IPS:GV na proporção de $85: 15$, umidade de condicionamento de $60 \%$, temperatura de $1^{\text {a }}$ e $2^{\text {a }}$ zona de 50 e $70^{\circ} \mathrm{C}$, respectivamente, de $3^{-a}$ e $4^{\text {a }}$ zona de $90^{\circ} \mathrm{C}$, vazão de alimentação de $12 \mathrm{~kg} \mathrm{~h}^{-1}$, velocidade de rosca de 300 rpm e matriz retangular com abertura de $7,5 \mathrm{~mm}$ de altura, 33,5mm de largura e $45 \mathrm{~cm}$ de comprimento. Após a extrusão, as amostras foram desidratadas em liofilizador L108 (Liotop, São Carlos, BRA) acoplado com bomba a vácuo DC.16D (DVP Vacuum Technology, Bologna, ITA).

\section{Solventes utilizados}

Os solventes utilizados para avaliar o teor de solubilização das proteínas foram: tampão fosfato em pH de 7,5 nas concentrações de 10, 20, 40, 60, 80 e 100mM; SDS nas concentrações de 1, 2, 3, 4 e $5 \%$; $\beta$-ME nas concentrações de $1,2,3$ e 4\%; Triton 
X-100 nas concentrações de 1, 2, 3 e 4\%; e ureia nas concentrações de $6,7,8,9$ e 10M.

Extração e quantificação das proteínas

A extração das proteínas foi realizada conforme descrito por CHIANG (2007). Resumidamente, $80 \mu \mathrm{g}$ de amostra (em base seca) foram pesados em microtubo de $2000 \mu \mathrm{L}$ e adicionados de $1500 \mu \mathrm{L}$ de solvente. Os microtubos foram incubados em banho-maria 304-TPA (Nova Ética, Vargem Grande Paulista, BRA) a $40^{\circ} \mathrm{C}$ por 2,5 horas, sendo que cada microtubo foi submetido à agitação em vórtex AP 56 (Phoenix, Araraquara, BRA) a cada 30 minutos. Em seguida, as amostras foram separadas em centrífuga Mikro 200R (Hettich Zentrifugen, Tuttlingen, DEU) a $10.000 \times \mathrm{g}$ por 30 minutos a $20^{\circ} \mathrm{C}$. O sobrenadante foi coletado em tubo de ensaio e a concentração de proteína solúvel, quantificado pelo método 46-13.01da AACC (2010) para as amostras extraídas com tampão fosfato, SDS, $\beta$-ME e Triton X-100, e pelo método DC Protein Assay da BIORAD, para as amostras extraídas com ureia, utilizando a albumina de soro bovino como padrão. Nesta etapa, as leituras foram realizadas em espectrofotômetro 415-1340 (Fluo Star Omega, Ortenberg, DEU) com comprimento de onda de $750 \mathrm{~nm}$. As análises foram realizadas em triplicata para a extração e em quadruplicata para as leituras em espectrofotômetro.

\section{Análise estatística}

Os dados foram avaliados pelo software Statistica 7.0 para análise de variância (ANOVA) e comparação de médias, através do teste de Tukey, com nível de significância de 5\%.

\section{RESULTADOS E DISCUSSÃO}

\section{Composição centesimal}

Os resultados da composição centesimal do IPS e do GV estão apresentados na tabela 1. A umidade foi quantificada para a correta proporção de IPS e GV para as mesclas dos ensaios. Verificouse que o IPS apresentou maiores valores de proteína e cinzas em relação ao $\mathrm{GV}$, o qual apresentou o maior teor de lipídeos, em que todos foram estatisticamente significativos $(\mathrm{P} \leq 0,05)$. Dessa forma, a quantidade de carboidratos foi maior para o GV. O teor proteico do IPS e do GV está de acordo com a RDC 268, de 23 de setembro de 2005, a qual estipula uma concentração mínima de 88 e $60 \%$ de proteína para o IPS e o GV, respectivamente. A lista de composição dos alimentos (National Nutrient Database for Standard Reference)
Tabela 1 - Composição centesimal do isolado proteico de soja e do glúten vital.

\begin{tabular}{lcc}
\hline Amostra & Isolado proteico de soja (\%) & Glúten vital (\%) \\
\hline Umidade & $6,15 \pm 0,14^{\mathrm{b}}$ & $8,09 \pm 0,09^{\mathrm{a}}$ \\
Proteínas $^{*}$ & $88,53 \pm 0,52^{\mathrm{a}}$ & $77,01 \pm 1,22^{\mathrm{b}}$ \\
Lipídeos $^{*}$ & $0,50 \pm 0,02^{\mathrm{b}}$ & $4,27 \pm 0,45^{\mathrm{a}}$ \\
Cinzas $^{*}$ & $4,45 \pm 0,25^{\mathrm{a}}$ & $0,92 \pm 0,09^{\mathrm{b}}$ \\
Carboidratos $^{* \#}$ & $6,52 \pm 0,58$ & $17,80 \pm 1,30$ \\
\hline
\end{tabular}

Média de três repetições \pm desvio padrão; ${ }^{*}$ valores expressos em base seca; fator de nitrogênio de 6,25 para o isolado proteico de soja e de 5,70 para o glúten vital; " carboidratos calculados por diferença (100-proteína-lipídeos-cinzas) e o desvio padrão calculado através da propagação de erros; médias com letras distintas na mesma linha apresentam diferença estatística entre si $(\mathrm{P}=0,05)$.

da United States Department of Agriculture (USDA, 2013 ) indica valores de lipídeos de 4,0\% para o IPS e de $1,85 \%$ para o GV. SCHMIELE et al. (2013a) obtiveram valores menores de lipídeos $(0,37 \%)$ e semelhantes em cinzas (4,31\%) para o IPS, em base seca. Avaliando amostra de IPS comercial, SCHMIELE et al. (2011) encontraram valores de lipídeos de 1,07\% e de cinzas de 3,49\%, em base seca. Em relação ao GV, ROSELL \& FOEGEDING (2007) encontraram valores menores para lipídeos $(3,0 \%)$, e apresentaram teores semelhantes para cinzas $(1,0 \%)$, ambos em base seca, em relação a este estudo. A diferença entre os valores de lipídeos destes autores para o IPS e o GV provavelmente está relacionado com a complexação da fração lipídica na matriz durante o processo de extração das proteínas, sendo, dessa forma, arrastada no processo de solubilização das proteínas.

Teor de proteína solubilizada nas diferentes concentrações dos solventes

A figura 1 apresenta a porcentagem de solubilização das proteínas nos solventes tampão fosfato, $\operatorname{SDS}$ e $\beta$-ME e a figura 2 apresenta a porcentagem de proteína solubilizada nos solventes Triton X-100 e ureia. Verificou-se que a quantidade de proteína solúvel para a amostra extrusada com baixa umidade foi maior na concentração de $40 \mathrm{mM}$ de tampão fosfato $(15,7 \%)$ e estatisticamente significativa $(\mathrm{P} \leq 0,05)$. $\mathrm{Na}$ amostra extrusada à alta umidade, não houve diferença entre as concentrações de tampão fosfato. O tampão fosfato solubiliza apenas proteínas no estado nativo (proteínas que não sofreram desnaturação e/ou interações químicas entre si) (LIU \& HSIEH, 2008).

A força iônica em $10 \mathrm{mM}$ de tampão fosfato provavelmente apresentou-se abaixo do necessário 


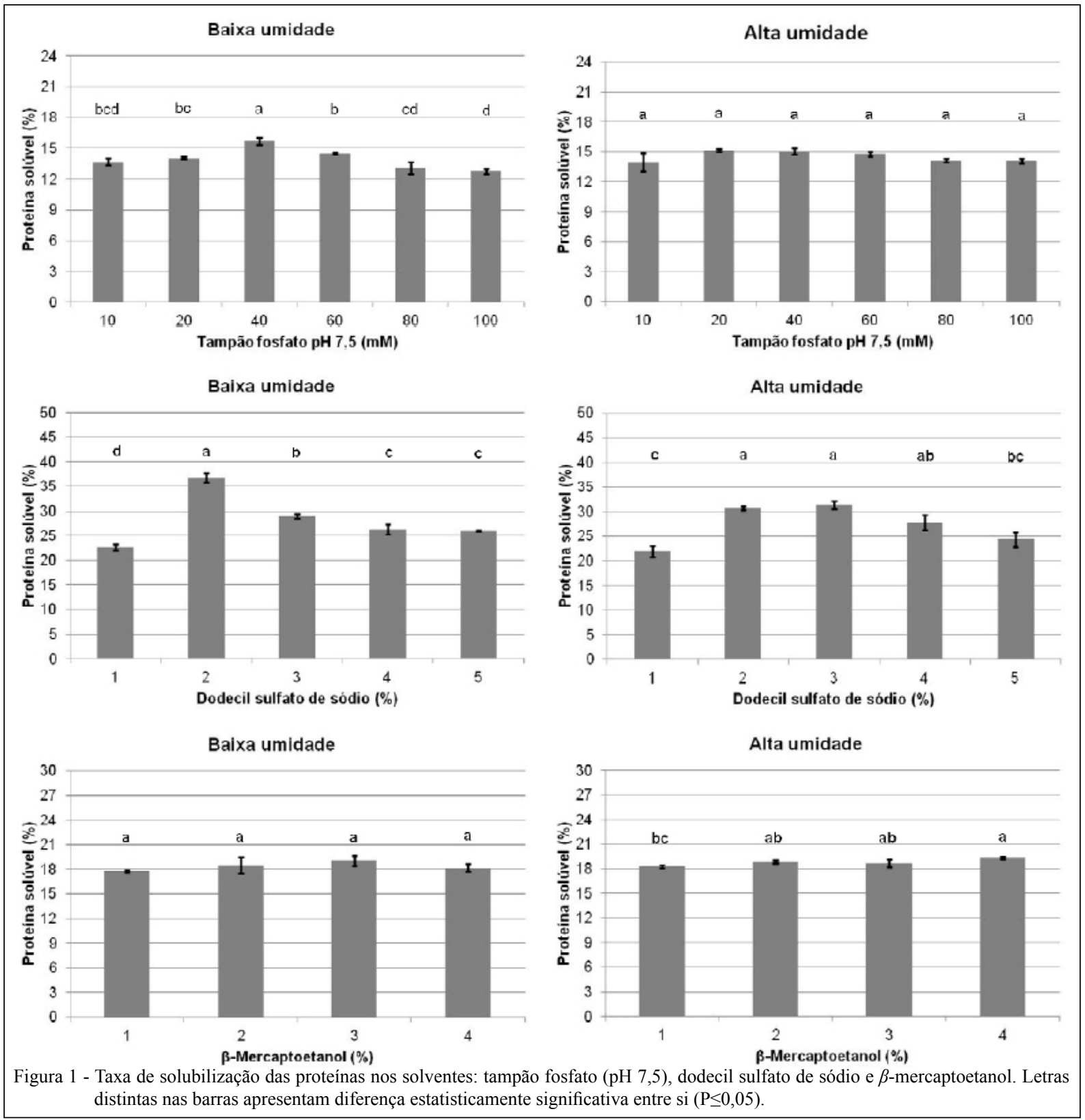

para a solubilização das proteínas, enquanto que forças iônicas iguais ou maiores de $60 \mathrm{mM}$ apresentaram efeito salting in, provocando a parcial precipitação de parte das proteínas, dificultando a solubilização destas no estado nativo (KANNAN et al., 2012).

A extração com $2 \%$ de SDS foi maior $(36,76 \%)$ para o processo com baixa umidade e estatisticamente diferente $(\mathrm{P} \leq 0,05)$ das demais concentrações. A extração de proteínas no processo em alta umidade não apresenta diferenças estatisticamente significativas para as concentrações de 2,3 e 4\%, com solubilização de $30,71,31,31$ e $27,85 \%$ das proteínas. O SDS é um reagente tensoativo iônico aniônico capaz de romper interações hidrofóbicas e iônicas ocorridas entre as proteínas durante o processo de extração. Provavelmente, o SDS transforma a estrutura proteica $\beta$-folha em $\alpha$-hélice, favorecendo a solubilidade proteica (KANNAN et al., 2012).

Em relação à extração de proteínas com $\beta$-ME, o uso de $2 \%$ de solvente extraiu $18,81 \%$ das proteínas e foi semelhante a 3 e $4 \%$, mas diferindo estatisticamente de $1 \%(\mathrm{P} \leq 0,05)$, para o processo em alta umidade. Em contrapartida, não houve diferença na solubilização proteica entre as concentrações de $\beta$-ME para a extrusão à baixa umidade, indicando a presença de ligações do tipo S-S, sendo estas mais

Ciência Rural, v.45, n.6, jun, 2015. 


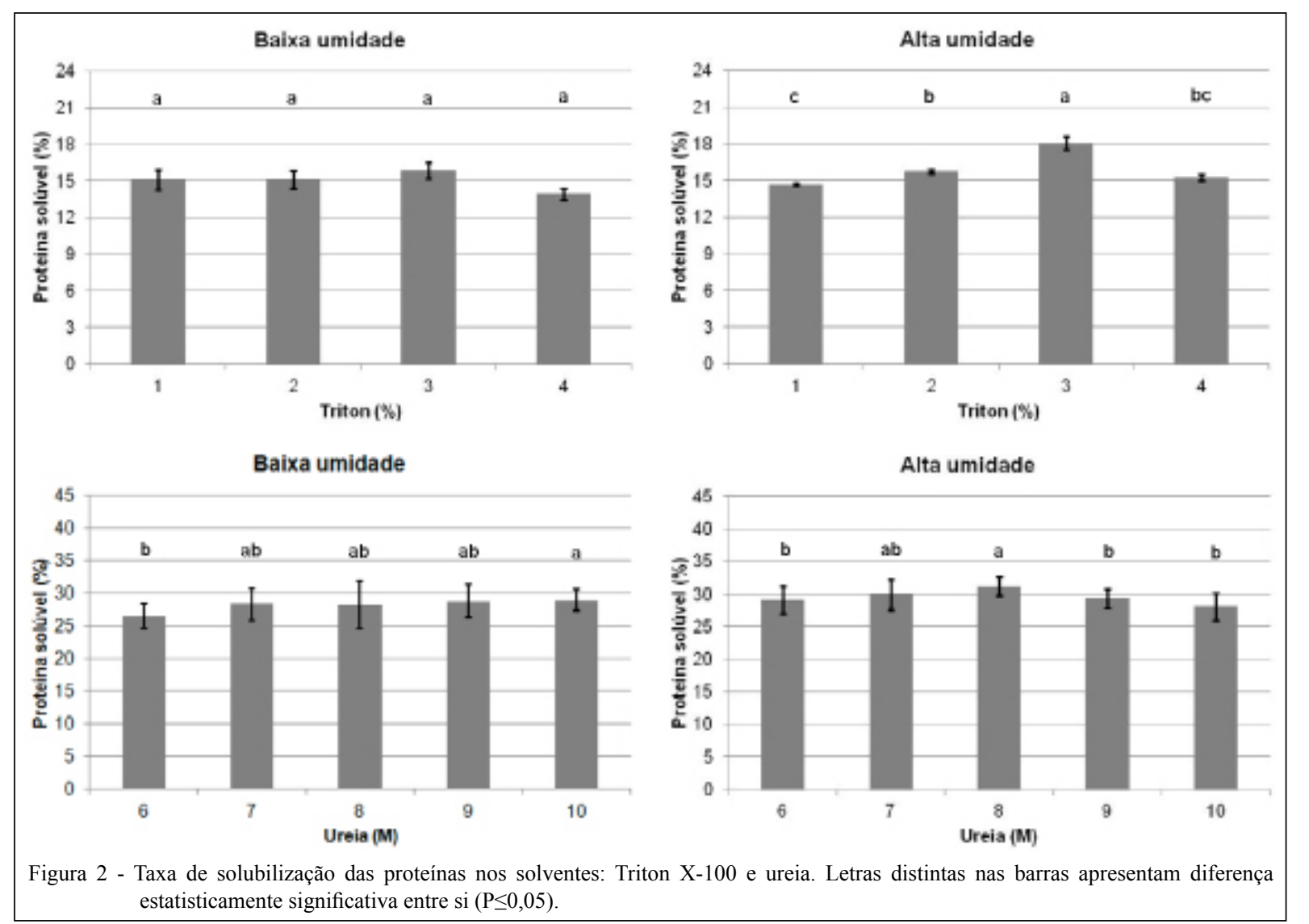

pronunciadas no processo à alta umidade. O $\beta$-ME é responsável pela ruptura de ligações dissulfeto (S-S), resultando em grupamentos dissulfídricos (S-H) (CHEN et al., 2011).

Nas concentrações de 1 a 4\% de Triton $\mathrm{X}-100$, para o processo de extrusão a baixa umidade, a extração de proteínas foi semelhante. No entanto, para o processo a alta umidade, $3 \%$ de Triton X-100 apresentou a maior solubilização de proteínas $(18,08 \%)$, sendo estatisticamente diferente $(\mathrm{P} \leq 0,05)$ em relação às demais concentrações. $O$ Triton X-100 é um reagente tensoativo não iônico (também conhecido como zwitterionic - anfótero) capaz de romper interações hidrofóbicas (LIU \& HSIEH, 2008), indicando assim que a maior incidência destas interações encontra-se no análogo de carne obtido no processo de extrusão a alta umidade.

Quando utilizada a ureia como solvente, a maior solubilização proteica foi obtida com 10M no processo de extrusão com baixa umidade, no entanto, não apresentou diferença estatisticamente significativa em relação a 7, 8 e 9M. Ao realizar o processo de extrusão por alta umidade, a maior extração foi atingida com uso de $8 \mathrm{M}$, a qual não apresentou diferença estatisticamente significativa em relação à $7 \mathrm{M}(\mathrm{P} \leq 0,05)$, sendo que a extração proteica com 6 e 7M de ureia também não apresentou diferença estaticamente significativa entre si $(\mathrm{P} \leq 0,05)$. A ureia solubiliza proteínas que apresentam interações não covalentes (LIU \& HSIEH, 2008).

Em ambos os processamentos, foi determinada a ocorrência de ligações dissulfeto (solubilizadas em $\beta$-ME). No processo a alta umidade, foi verificado que a formação de ligações de hidrogênio e de ligações iônicas (solubilizadas em ureia) foram mais pronunciadas. No processo a baixa umidade, houve maior incidência de ligações de hidrogênio (solubilizadas em ureia) e de interações hidrofóbicas e iônicas (solubilizadas em SDS).

\section{CONCLUSÃO}

As maiores extrações proteicas foram obtidas com 40mM de tampão fosfato ( $\mathrm{pH} 7,5), 2 \%$ de dodecil sulfato de sódio, $2 \%$ de $\beta$-mercaptoetanol, $3 \%$ de Triton X-100 e 7M de ureia. As concentrações mencionadas para cada tipo de solvente mostrouse eficaz para maximizar a extração de proteínas de análogo de carne, obtidas por extrusão a baixa e alta umidade. Com estas concentrações, maximizou-

Ciência Rural, v.45, n.6, jun, 2015. 
se a extração da proteína e minimizou-se a geração de resíduos, os quais necessitam de tratamento adequado para o descarte. As principais interações proteína-proteína encontradas nas amostras foram as interações hidrofóbicas no processo a alta umidade e as interações iônicas no processo a baixa umidade. Além disso, há a possibilidade de que pode ocorrer sinergismo entre o tipo de ligações e/ou interações químicas que ocorrem entre as proteínas durante o processo de extrusão termoplástica de proteínas vegetais, na obtenção de análogos de carne.

\section{AGRADECIMENTOS}

Os autores agradecem ao Conselho Nacional de Desenvolvimento Científico e Tecnológico (CNPq) pela concessão da bolsa de estudos (Processo 140331/2009-3) e pelo financiamento (Processo 483247/2012-0), à Solae, pela doação do isolado proteico de soja e à Labonathus, pela doação do glúten vital.

\section{REFERÊNCIAS}

AACC (AMERICAN ASSOCIATION OF CEREAL CHEMISTS). Approved methods. 11ed. v.1 e 2. St. Paul, 2010. 1200p.

BRASIL. Resolução RDC ANVISA/MS nº 268, de 22 de setembro de 2005. Regulamento técnico para produtos proteicos de origem animal. Diário OficialdaUnião,Brasília,DF,23 set.2005. Disponível em: <http://e-legis.anvisa.gov.br/>. Acesso em: 04 mai. 2013.

CHEN, F.L. et al. Chemical cross-linking and molecular aggregation of soybean protein during extrusion cooking at low and high moisture content. LWT - Food Science and Technology, v.44, n.4, p.957-962, 2011. Disponível em: <http:// www.sciencedirect.com/science/article/pii/S0023643810004305>. Acesso em: 05 maio 2013. doi: 10.1016/j.lwt.2010.12.008.

CHIANG,A.Protein-proteininteractionofsoyproteinisolatefrom extrusion processing. 2007. 90f. Dissertation (Master of Science) - Faculty of the Graduate School, University of Missouri-Columbia.

DAY, L.; SWANSON, B.G. Functionality of protein-fortified extrudates. Comprehensive Reviews in Food Science and Food Safety, v.12, n.5, p.546-564, 2013. Disponível em: $<$ http:// onlinelibrary.wiley.com/doi/10.1111/1541-4337.12023/abstract>. Acesso em: 05 ago. 2014. doi: 10.1111/1541-4337.12023.

KANNAN, A. et al. Food proteins - peptides. In: HETTIARACHCHY, N.S. et al. Food proteins and peptides chemistry, functionality, interactions, and commercialization. Boca Raton, CRC, 2012. p.1-24.
LIN, S. et al. Texture and chemical characteristics of soy protein meat analog extruded at high moisture. Journal of Food Science, v.65, n.2, p.264-269, 2000. Disponível em: <http://onlinelibrary.wiley. com/doi/10.1111/j.1365-2621.2000.tb15991.x/abstract>. Acesso em: 05 ago. 2014. doi: 10.1111/j.1365-2621.2000.tb15991.x.

LIU, K.; HSIEH, F-H. Protein-protein interactions during highmoisture extrusion for fibrous meat analogues and comparasion of protein solubility methods using different solvent systems. Journal of Agricultural and Food Chemistry, v.56, n.8, p.26812687, 2008. Disponível em: $<$ http://pubs.acs.org/doi/pdf/10.1021/ jf073343q > . Acesso em: 29 maio 2013. doi: 10.1021/jf073343q.

LOUDON, M. Organic chemistry. 5.ed. New York: Oxford University, 2009. 1374p.

ROSELL, C.M; FOEGEDING, A. Interaction of hydroxypropylmethylcellulose with gluten proteins: Small deformation properties during thermal treatment. Food Hydrocolloids, v.21, n.7, p.1092-1100, 2007. Disponível em: $<$ http:// www.sciencedirect.com/science/ article/pii/S0268005X0600169X>. Acesso em: 05 maio 2013. doi: 10.1016/j.foodhyd.2006.08.003.

SATHE, S.K. Protein solubility and functionality. In: HETTIARACHCHY, N.S. et al. Food proteins and peptides chemistry, functionality, interactions, and commercialization. Boca Raton: CRC, 2012. p.94-124.

SCHMIELE, M. et al. Influência da adição de farinha integral de aveia, flocos de aveia e isolado proteico de soja na qualidade tecnológica de bolo inglês. Boletim do Centro de Pesquisa de Processamento de Alimentos, v.29, n.1, p.71-82, 2011. Disponível em: <http://ojs.c3sl.ufpr.br/ojs-2.2.4/index.php/alimentos/article/ viewArticle/22751>. Acesso em 05 maio 2013.

SCHMIELE, M. et al. Massa alimentícia sem glúten com elevado teor proteico obtida por processo convencional. Ciência Rural, v.43, n.5, p.908-914, 2013. Disponível em: <http://www.scielo. br/scielo.php? script $=$ sci_arttext\&pid $=$ S0 10384782013000500 026\&lng $=\mathrm{pt} \& \mathrm{nrm}=\mathrm{iso} \& \mathrm{t} \operatorname{lng}=\mathrm{pt}>$. Acesso em: 17 maio 2013. doi: $10.1590 / \mathrm{S} 010384782013000500026$.

SCHMIELE, M. et al. Meat analogue produced with soy protein isolate and vital gluten by thermoplastic extrusion: technological, physicochemical and nutritional characteristics. In: WALTER, D.B. Gluten: sources, composition and health effects. Hauppauge: Nova Science Publishers, 2013. p.87-106. ISBN 9781626183445.

SOLOMONS, T.W.G; FRYHLE, C.B. Química orgânica 1. 8.ed. Rio de Janeiro, LTC Livros técnico e científicos, 2005. 715p.

STEEL, C.J. et al. Thermoplastic extrusion in food processing. In: EL-SONBATI, A.Z. Thermoplastic elastomers. Croátia: Intech, 2012. p.265-290. 